\title{
Physical basis of rolling bearing vibration formation of structural
}

\author{
Mikolay Hruntovich ${ }^{1, *}$, Nadzeya Hruntovich $^{1}$, Aliaksei Kapanski ${ }^{1}$, Larisa Markaryants ${ }^{2}$, and Elena Gracheva ${ }^{3}$ \\ ${ }^{1}$ Sukhoi State Technical University of Gomel, Prospect Octiabria, 48, 246746, Gomel, Republic of Belarus \\ ${ }^{2}$ Federal State Budgetary Educational Institution of Higher Education «Moscow State Linguistic University» (MSLU), 119034, 38 \\ Ostozhenka St. Moscow \\ ${ }^{3}$ Kazan State Power Engineering University, str. Krasnoselskaya, 51, 420066, Kazan, Russia
}

\begin{abstract}
The problem of increasing the reliability of detecting defects, both in new rolling bearings and the ones having already been in operation is current. The article describes the physical foundations of vibration of rolling bearings, caused by the different dimensions of the rolling elements and increased microwaves of the rings. A classification of rolling bearing defects was proposed, as well as calculation formulas for vibration frequencies corresponding to the indicated defects. It is shown that the vibration level at the overturning frequency depends on the gap size and the rotor mass. As an example, possible defects of rolling bearing No.310 were considered and their vibration frequencies were calculated. The frequency range in which defects of the rings and rolling elements appear was installed. An explanation of the reasons for the occurrence of high-frequency vibration was given. The combination of defects in the rolling elements of different dimensions and imbalance in the rotor causes the intensive development of microshells on the rolling bearing rings. Examples of experimental vibroacoustic characteristics were given to illustrate the physical processes of vibration in rolling bearings with various defects.
\end{abstract}

\section{Introduction}

The first works on the use of vibration for detecting defects in induction motors appeared in the 70 s of the last century [1-4]. They tried and still do trying to diagnose a rolling bearing by a general level in the range of 10-200 Hz, vibration measurement in microns [5]. Later they began to carry out vibration diagnostics according to the general level in the range of 10-1000 $\mathrm{Hz}$, and vibration was measured in millimeters per second (mm / s) [6]. With the advent of microprocessor devices and computer vibroacoustic systems, the vibration analysis of rolling bearings in the range up to $20,000 \mathrm{~Hz}$ was made. Vibration is measured in vibration acceleration $(\mathrm{m} / \mathrm{s} 2$ or $\mathrm{dB})$. Mathematical formulas were determined to calculate the vibration frequencies of the bearings during the operation of the mechanism. Approximate formulas are sometimes used to calculate vibration frequencies [7]. The authors of many works [810] derive formulas based on the physics of bearings. This takes into account the contact angle of the rolling elements. In works $[9,10]$, the angle of contact is not taken into account. Various methods of processing vibration spectra were developed: direct analysis of the vibration spectrum of mechanisms at informative frequencies in any range $[4,9,10]$, according to the envelope spectrum [8], and wavelet transform $[11,12]$. The reliability of detecting defects according to the existing methods is no more than $50 \%$, since these methods do not take into consideration the physical processes of vibration.

\section{Research results}

The conducted research of vibroacoustic characteristics on a special diagnostic stand of both new bearings and the ones having been in operation made it possible to reconsider the theory of physical processes of vibration of rolling bearings. More than 100 bearings, both new and the ones having been in operation were tested.

The shaft rotates with an angular velocity $\omega_{r}$ (figure 1). Since the ball simultaneously rolls on a stationary outer surface, the point of contact $\mathrm{P}$ is the instantaneous center of velocities.

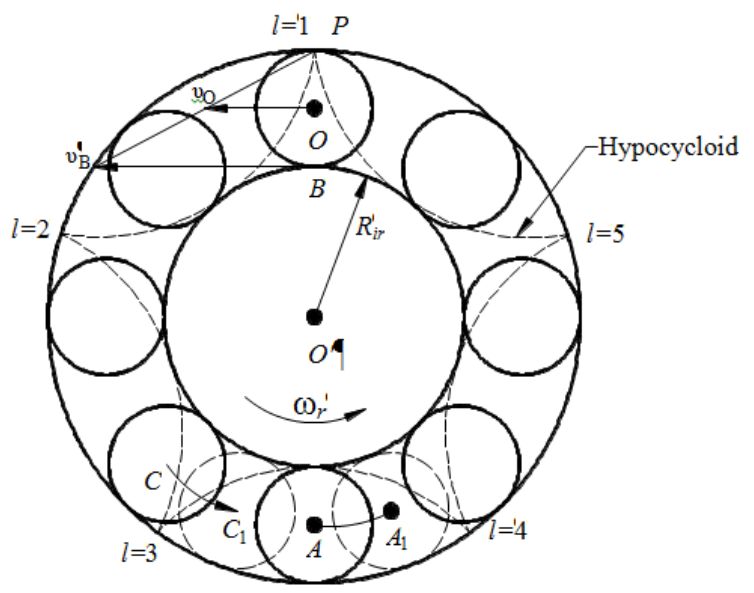

Fig. 1. Diagram to explain the overturning of a shaft in a bearing in an unstable state.

\footnotetext{
* Corresponding author: gruntovich@tut.by
} 
Using the concept of the instantaneous center of velocities, we define the linear velocity of point $\boldsymbol{O}$ :

$$
v_{o}=0.5 v_{B}=\frac{v_{r} R_{i r}}{2},
$$

where $R_{i r}$ - working surface radius of the rolling bearing inner ring, $\mathrm{mm}$.

With the known values of the inner ring diameter $d$, $\mathrm{mm}$ and the outer ring diameter $\mathrm{D}, \mathrm{mm}$, the rolling bearing parameters $R_{i r}$ is calculated by the formula:

$$
R_{i r}=\frac{(d+D)}{4}-r_{s},
$$

where $r_{s}$ - the radius of the rolling elements, $\mathrm{mm}$.

Therefore, the angular velocity of the center of the ball:

$$
\Omega=\frac{v_{O}}{R_{i r}+r_{s}}=\frac{\omega_{r} R_{i r}}{2}\left(R_{i r}+r_{s}\right) .
$$

Then the frequency of rotation of the center of the ball (separator) is determined by the formula:

$$
f_{s}=\frac{f_{r} \cdot R_{i r}}{2} \cdot\left(R_{i r}+r_{s}\right)
$$

Since the linear velocity of point B is equal to $\omega_{r}$. $R_{i r}$, the angular velocity of the ball around its own axis is equal to:

$$
\omega_{s}=\frac{\nu_{B}}{2} r_{s}=\frac{\omega_{r} R_{i r}}{r_{s}} \text { or } f_{c 1}=\frac{f_{r} R_{i r}}{2 r_{s}} .
$$

The ball rotates not only around its own axis with frequency, but also relatively to the separator. Consequently, defects of the balls, separator, as well as insufficient lubrication influence the frequency.

For electric motors that are installed on horizontal arms, in addition to the considered frequency spectrum of vibration with a large wear of rolling bearings, vibration with a frequency of the rotor shaft overturning is typical. The vibration frequency of the shaft is calculated by the formula:

$$
f_{\text {or }}=f_{s} Z_{R}
$$

where $Z_{R}$ - number of rolling elements.

Let us explain the physical meaning of the overturning of a shaft in a rolling bearing. During the operation of the mechanism, when the center of the shaft $\mathrm{O}$ 'coincides with the center of the ball $\mathrm{A}$, the shaft is in an unstable position. As the shaft rotates further, ball A moves to position $\mathrm{A} 1$ and the shaft tilts onto ball $C\left(C_{1}\right)$. At the moment of collision of the shaft, ball and rings, the kinetic energy is equal to the work of the force:

$$
\frac{m v_{0}^{2}}{2}=F h,
$$

where $m$ is the mass of the rotor, $v_{0}$ is the speed of the shaft at the moment of impact, $F$ is the radial force, $h$ is the clearance in the bearing.

The impact force depends on the clearance and the rotor weight. The vibration of a bearing depending on the size of the clearance was first described in $[14,15$, $17,18]$.

In case if an imbalance of the rotor occurs in the presence of rolling elements of different dimensions, and the outer ring is placed in the end shield with an interference fit, then a pothole will be formed on the outer ring. Such bearings were encountered during the study. Measurements of the stress concentration on the outer ring of the used bearings showed its variation within 40-300 A / m.

Table 1 shows the proposed classification of rolling bearing defects, formulas for calculating vibration frequencies after examining the physical processes of vibration of bearings on a diagnostic stand, as well as the values of these frequencies for bearing № 310 .

In practice, such defects as work hardening (brinelling) on the rings are often encountered. This happens in the following cases:

- firstly, when transporting electric motors;

- secondly, when several pumping units are located on the same foundation. At the same time, if the operating pump unit has a large vibration, then the second non-operating pump unit will be hardened on the bearings. Formulas 1, 2, 4, 5,7,8 (table 1) can justify the vibration spectrum of bearings up to $600 \mathrm{~Hz}$.

During the experiments on the diagnostic stand, it was established that if there is no different dimensionality of the rolling bodies and their versatility, then in the frequency range up to $500 \mathrm{~Hz}$ the vibration level is minimal $40-50 \mathrm{~dB}$ (at $\mathrm{a}_{0}=3 \cdot 10-4 \mathrm{~m} / \mathrm{s} 2$ ). But if there are microwaves or micro-shells in these bearings on the rings, then in the frequency range of $600-5000 \mathrm{~Hz}$ the vibration can reach $90 \mathrm{~dB}$. This phenomenon can be explained as follows. When the rolling bodies rotate between the bearing rings, any selected precise on the surface of the ball moves along the hypocycloid [15]. It touches the outer ring once and touches the inner ring $\mathrm{m}$ times:

$$
l=\left(\frac{R_{i r}+2 r_{s}}{2 r_{s}}\right) \text { and } m=\frac{R_{i r}}{2 r_{s}} .
$$

The calculations showed that $l$ and $m$ are never integers. But the number of touch points is infinite. This gives us the right to assign any number when choosing $K$ (the number of harmonics). In addition, during long-term operation and with poor lubrication, micro-shells gradually form on the rings due to collisions when the shaft rolls over. Taking into account the angle of contact of the rolling elements, the contact area is formed in the form of an elongated ellipse with an area of 1.5-4 $\mathrm{mm}^{2}$, depending on the type of bearing. In this small area, 3 to 10 micro-shells of different sizes can be identified. As a result, it turns out that the entire surface of the rings is covered with micro-shells. All of this together causes high frequency vibration. 
Table 1. Defects of rolling bearings and their vibration frequency for bearing No. 310 according to the proposed classification of defects.

\begin{tabular}{|c|c|c|c|}
\hline № & $\begin{array}{c}\begin{array}{c}\text { Formulas for calculating vibration } \\
\text { frequencies }\end{array} \\
\end{array}$ & Defect frequency, $\mathrm{Hz}$ & $\begin{array}{l}\text { Vibration frequency identification of possible } \\
\text { defects }\end{array}$ \\
\hline 1 & $f_{s}=\frac{f_{r} \cdot R_{i r}}{2\left(R_{i r}+r_{s}\right)}$ & 19.05 & $\begin{array}{l}\text { Rotation frequency of the separator around the shaft } \\
\text { center. At this frequency appears wear separator. }\end{array}$ \\
\hline 2 & $f_{o r}=f_{s} \cdot Z_{R}$ & 152.4 & $\begin{array}{l}\text { Frequency of overturning of a shaft in a rolling } \\
\text { bearing causing defects due to the different } \\
\text { dimensions of the rolling elements. }\end{array}$ \\
\hline 3 & $\begin{aligned} f_{s}^{\prime} & =f_{s} Z_{R} K \\
K & =2 \ldots 25\end{aligned}$ & $609 \ldots 3807$ & $\begin{array}{l}\text { Frequency of microwelling or microwaving on the } \\
\text { outer ring. }\end{array}$ \\
\hline 4 & $f_{i r}^{\prime}=f_{r}-f_{s}$ & 30.96 & $\begin{array}{l}\text { Frequency of movement (sliding) of the rolling } \\
\text { elements relative to the inner ring. At this frequency, } \\
\text { the wear of the inner ring appears. }\end{array}$ \\
\hline 5 & $f_{r e}=\left(f_{r}-f_{s}\right) \mathrm{Z}_{R}$ & 247 & $\begin{array}{l}\text { The vibration frequency of the inner ring due to the } \\
\text { different dimensions of the rolling elements. }\end{array}$ \\
\hline 6 & $\begin{array}{c}f_{r e}^{\prime}=\left(f_{r}-f_{s}\right) \mathrm{Z}_{R} K \\
K=4 \ldots 25\end{array}$ & $988 \ldots 6175$ & Microwaves or microwells in the inner ring. \\
\hline 7 & $f_{c 1}=\frac{f_{r} R_{i r}}{2 r_{s}}$ & 79.9 & $\begin{array}{l}\text { The frequency of rotation of the rolling elements } \\
\text { around their own axis. At this frequency, the } \\
\text { versatility of rolling bodies can be manifested. }\end{array}$ \\
\hline 8 & $f_{c 2}=\frac{f_{r} R_{i r}}{2 r_{s} Z_{R}}$ & 639.2 & $\begin{array}{l}\text { The beating frequency of the rolling elements } \\
\text { between the rings due to their different dimensions. }\end{array}$ \\
\hline 9 & $\begin{array}{l}f_{c 1}^{\prime}=f_{c 1} \cdot K \\
K=4 \ldots 25\end{array}$ & $320 \ldots 2000$ & $\begin{array}{l}\text { Frequency of occurrence of micro-shells on rolling } \\
\text { bodies. }\end{array}$ \\
\hline 10 & $\begin{aligned} f_{c 2}^{\prime} & =f_{c 2} \cdot K \\
K & =4 \ldots 25\end{aligned}$ & $2556 \ldots 15975$ & $\begin{array}{l}\text { Frequency of occurrence of micro-shells on rolling } \\
\text { bodies. }\end{array}$ \\
\hline
\end{tabular}

Note. Bearing parameters 7A310: inner ring diameter $d=50 \mathrm{~mm}$, outer ring diameter $D=110 \mathrm{~mm}, Z_{R}=8, R_{i r}=30.47 \mathrm{~mm}, r_{s}=$ $9.52 \mathrm{~mm}$.

Figure 2 shows the frequency ranges of vibration with various defects in rolling bearing № 310. The frequency $80 \mathrm{~Hz}$ is the beat frequency of the rolling elements. The frequency of $152 \mathrm{~Hz}$ is the frequency of shaft overturning caused by the different dimensions of the rolling elements. The frequency $247 \mathrm{~Hz}$ is the vibration frequency of the inner ring due to the different dimensions of the rolling elements.

By the type of vibroacoustic characteristics in the high frequency region, it is possible to evaluate the uniformity or unevenness of the wear of the rings. Figure 3 (a) shows the vibroacoustic characteristics of rolling bearing № 318, which indicate a clear uneven wear of the ring surface. In the vibration spectrum, areas with increased vibration are highlighted, exceeding the minimum value by $10 \mathrm{~dB}$. At the same time, vibration in the region of low frequencies up to $600 \mathrm{~Hz}$ is minimal, which indicates the absence of the rolling elements of different dimensions.

Figure 3 (b) shows the vibroacoustic characteristics

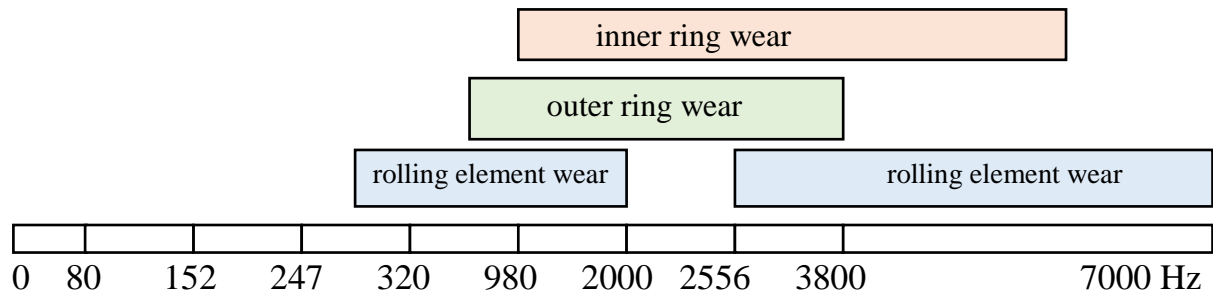

Fig. 2. Illustration of frequency ranges of vibration of rolling bearing elements № 310 when modeling defects by changing the number of harmonics $K=4 \ldots 25$. 


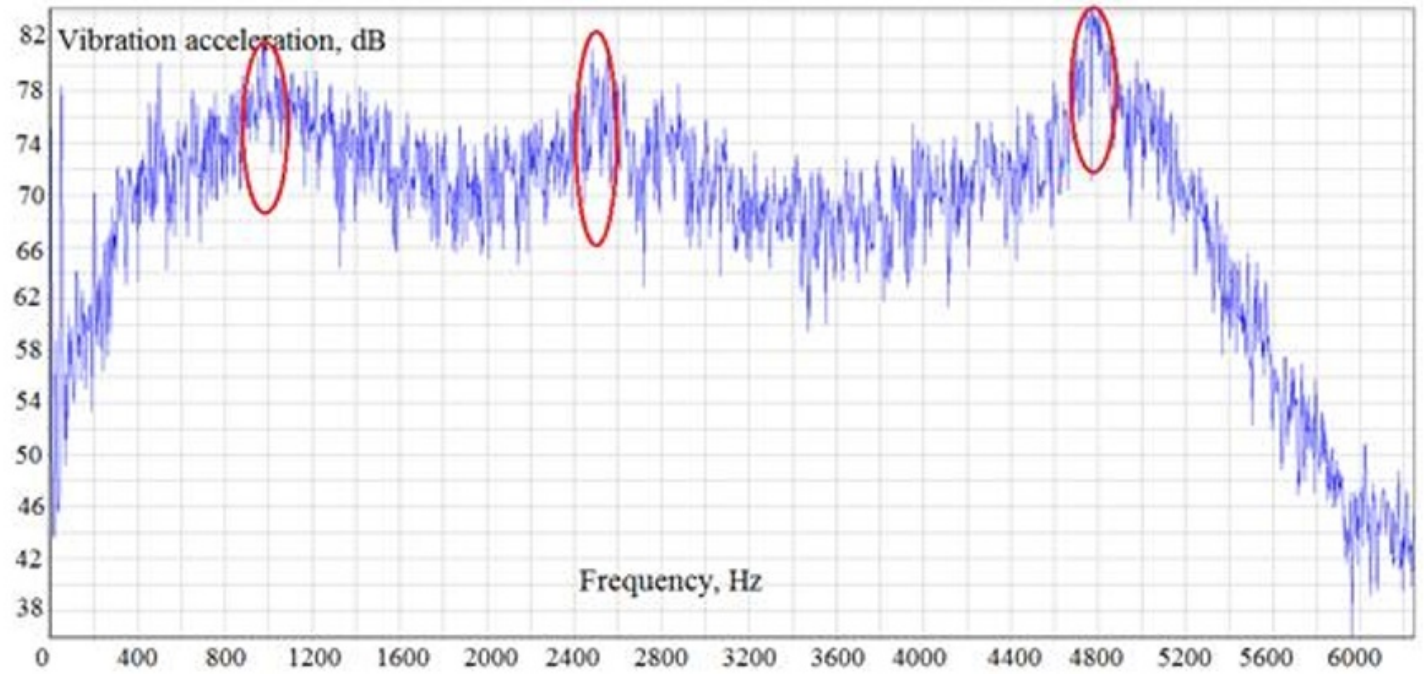

a)

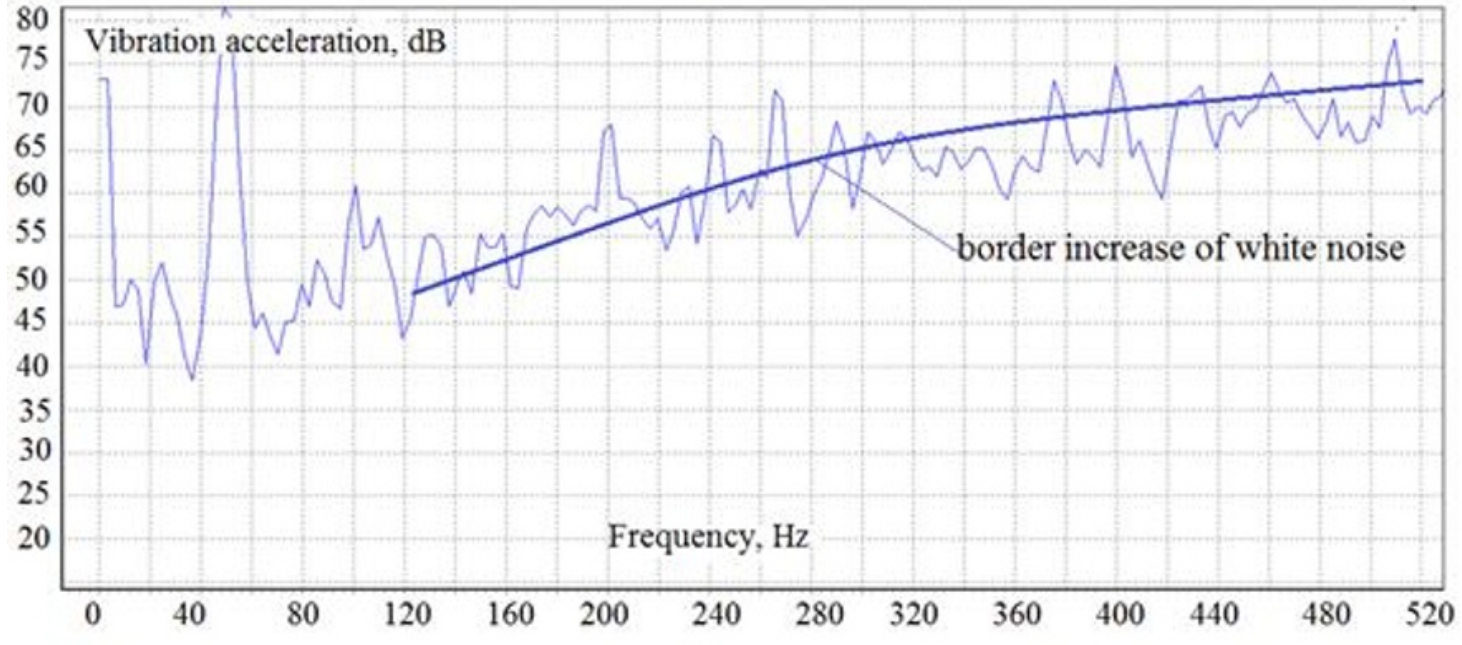

b)

Fig. 3. Vibroacoustic characteristics: a - rolling bearing №318; b- rolling bearing 6205-2RS.

of the $6205-2 \mathrm{RS}$ rolling bearing. High vibration at $50 \mathrm{~Hz}$ is the mains power supply interference. An increase in vibration from $40 \mathrm{~dB}$ at a frequency of $40 \mathrm{~Hz}$ to $78 \mathrm{~dB}$ at a frequency of $500 \mathrm{~Hz}$ indicates that the rolling elements and microwaves on the rings are of different dimensions. White noise $i$ the most important characteristic of rolling bearing wear.

\section{Conclusions}

1. Numerous experiments to study the vibration of new and used rolling bearings made it possible to propose a new classification of defects, to derive formulas for calculating the vibration frequencies of these defects.

2 . Experiments showed that the vibration of bearings up to $600 \mathrm{~Hz}$ is caused by overturning of the shaft in the bearing, vibration of the inner ring and beating of the rolling elements between the rings with a significant difference in size of the rolling elements.

3. It was determined that the vibration of new bearings in the range of more than $800 \mathrm{~Hz}$ depends significantly on the microwaves of the rings (processing class).

4. As a result of the examination of used rolling bearings, it was found that with a significant difference in the size of the rolling elements and in case of installing the outer ring with an interference fit, the bearing life is limited due to the formation of a pothole on the outer ring.

5. Micro-shells on the inner and outer rings can increase vibration of rolling bearings both in different frequency ranges and in the same frequency range.

\section{References}

[1] V.A. Avakyan, Diagnostics of vibration sources of machines taking into account amplitude modulation, Electrical Engineering, 2, 58-61 (1978)

[2] B.B. Voronetsky, E.R. Kucher, Magnetic noise of three-phase asynchronous short-circuited electric motors (Moscow, JI, Gosenergoizdat, 1957) 76 
[3] V.I. Popkov, Vibroacoustic diagnostics and reduction of vibration activity of ship mechanisms (Leningrad, Shipbuilding, 1974) 224

[4] N.V. Gruntovich, K.P. Putilin, A.A. Starochkin, Technical diagnostics of induction motors (Kiev, Society Knowledge, 1980) 35

[5] STP 33243.20.366-16, Norms and volumes of testing of electrical equipment of the Belarusian power system, State Production Association Belenergo, Minsk (2016)

[6] ISO 10816-3, Mechanical vibration - Evaluation of machine vibration by measurements on nonrotating parts

[7] A.V. Rusov, Spectral vibration diagnostics (Perm, 1996) 176

[8] A.V. Barkov, A.V. Barkova, A.Y. Azovtsev, Monitoring and diagnosis of rotary machines by vibration (Sankt-Petersburg, 2000) 169

[9] Nic.Vas. Hruntovich, I.V. Petrov, Means of vibrodiagnostics of rotary machines, Agricultural technique and power supply 8, 4, 40-50 (2015)

[10] Nic.Vas. Hruntovich, Installation, commissioning and use of electrical equipment (Minsk, 2013) 271

[11] V.I. Dubrovin, G.V. Fedoronchik, Diagnostics of rolling bearing defects using wavelet transform, Standardization and Metrology, 132-134 (2008)

[12] Ch. Chewie, An Introduction to Wavelets (M., Mir, 2001) 412

[13] S.M. Targ, A short course in theoretical mechanics (Moscow, Higher school, 2002) 416

[14] B.V. Pavlov, Diagnostics of "diseases" of machines, Ed. 2nd, rev. and add. (Moscow, Kolos, 1978) 143

[15] Nic.Vas. Hruntovich, I.V. Petrov, D.V. Kirdishev, Hypocycloid vibration frequency of rolling bearings, Modern issues of energy saving and energy efficiency in technical system, Tambov, 288-289 (25-27 April 2016)

[16] E.I. Gracheva, Estimation of electric power losses in low-voltage switching devices, News of higher educational institutions, Energy problems, 74-81 (2009)

[17] A.A. Shpiganovich, K.A. Pushnitsa, E.V. Churkina, O.V. Fedorov, Features of the operation of power supply systems of ferrous metallurgy enterprises, Ferrous metals, 5, 56-61 (2017)

[18] N.V. Hruntovich, A.A. Kapanski, I.V. Petrov, E.E. Kostyleva, Vibration diagnostic of electric motor roller bearings, EDP Sciences, E3S Web of Conferences 124, 02008 (2019) 